\title{
Zinc-Vacancy-Donor Complex: A Crucial Compensating Acceptor in ZnO
}

\author{
J. E. Stehr, ${ }^{1, *}$ K. M. Johansen, ${ }^{2}$ T. S. Bjørheim, ${ }^{3}$ L. Vines,${ }^{2}$ B. G. Svensson, ${ }^{2}$ W. M. Chen, ${ }^{1}$ and I. A. Buyanova ${ }^{1, \dagger}$ \\ ${ }^{1}$ Department of Physics, Chemistry and Biology, Linköping University, 58183 Linköping, Sweden \\ ${ }^{2}$ Department of Physics, Centre for Materials Science and Nanotechnology, \\ University of Oslo, N-0316 Oslo, Norway \\ ${ }^{3}$ Department of Chemistry, Centre for Materials Science and Nanotechnology, \\ University of Oslo, N-0318 Oslo, Norway
}

(Received 6 May 2014; revised manuscript received 26 July 2014; published 22 August 2014)

\begin{abstract}
The aluminum-zinc-vacancy $\left(\mathrm{Al}_{\mathrm{Zn}}-V_{\mathrm{Zn}}\right)$ complex is identified as one of the dominant defects in Al-containing $n$-type $\mathrm{ZnO}$ after electron irradiation at room temperature with energies above $0.8 \mathrm{MeV}$. The complex is energetically favorable over the isolated $V_{\mathrm{Zn}}$, binding more than $90 \%$ of the stable $V_{\mathrm{Zn}}$ 's generated by the irradiation. It acts as a deep acceptor with the $(0 /-)$ energy level located at approximately $1 \mathrm{eV}$ above the valence band. Such a complex is concluded to be a defect of crucial and general importance that limits the $n$-type doping efficiency by complex formation with donors, thereby literally removing the donors, as well as by charge compensation.
\end{abstract}

DOI: 10.1103/PhysRevApplied.2.021001

Transparent conductive oxides (TCOs) are currently employed in a wide variety of applications ranging from light emission and light harvesting to touch screens. At the moment, the most commonly used TCO is indium tin oxide, but a steep increase of the indium price in recent years, partly because of a limited abundance, has urged a widespread search for alternative materials. One of the most promising candidates is $\mathrm{ZnO}$ [1-3], since it is transparent to visible light, nontoxic, widely abundant, and cheap. Device applications of $\mathrm{ZnO}$ require reliable and precise control of its electrical and optical properties, which can be largely affected by intrinsic defects and impurities. Here, the key point defects to be considered include zinc vacancies $\left(V_{\mathrm{Zn}}\right)$, zinc interstitials $\left(\mathrm{Zn}_{i}\right)$, oxygen vacancies $\left(V_{\mathrm{O}}\right)$, and oxygen interstitials $\left(\mathrm{O}_{i}\right)$. Among them, $V_{\mathrm{Zn}}$ is probably the most relevant defect, since it has the lowest formation energy among native point defects in $n$-type $\mathrm{ZnO}$ [1] and is commonly found in bulk and nanostructured materials [4-8]. $V_{\mathrm{Zn}}$ is also suggested to be the origin of the observed $n$-type doping limit in $\mathrm{ZnO}[9,10]$ by forming complexes with donors leading to their compensation [11-13]. Therefore, it is crucial to understand the formation of intrinsic defects, especially $V_{\mathrm{Zn}}$, and their interaction with extrinsically important impurities such as shallow dopants in $\mathrm{ZnO}$, which remains far from complete.

In this study, we use electron irradiation with variable energies to generate point defects either solely on the $O$ sublattice (when the irradiation energy $E_{\text {irr }}=$ $0.45-0.8 \mathrm{MeV}$ ) or on both $\mathrm{Zn}$ and $\mathrm{O}$ sublattices (when

\footnotetext{
*Corresponding author. janst@ifm.liu.se

${ }^{\dagger}$ Corresponding author. irb@ifm.liu.se
}

$E_{\text {irr }}>0.8 \mathrm{MeV}$ ) [14,15]. The atomic structure and chemical composition of the defects are then identified by employing electron paramagnetic resonance (EPR) spectroscopy [16].

Nominally undoped melt-grown and monocrystalline $\mathrm{ZnO}$ from Cermet Inc. with an electron concentration of $1 \times 10^{17} \mathrm{~cm}^{-3}$ at room temperature (RT) is utilized, subjected to electron irradiation performed at RT by using $E_{\text {irr }}$ of $0.4,0.6,0.8$, and $1.2 \mathrm{MeV}$ and fluences $\Phi=(4-5) \times 10^{17} \mathrm{~cm}^{-2}$ [15]. The dominant residual impurities are found to be $\mathrm{Al}, \mathrm{Fe}$, and $\mathrm{Si}$ with atomic concentrations of approximately $3.5 \times 10^{16} \mathrm{~cm}^{-3}$, approximately $5.3 \times 10^{16} \mathrm{~cm}^{-3}$, and $(2-3) \times 10^{17} \mathrm{~cm}^{-3}$, respectively, by using secondary ion mass spectrometry (SIMS). No other impurities are found with a concentration above approximately $5 \times 10^{15} \mathrm{~cm}^{-3}$, with a possible exception of $\mathrm{H}$ being below its detection limit of $5 \times 10^{17} \mathrm{~cm}^{-3}$, consistent with reported values for a similar type of $\mathrm{ZnO}$ [17]. EPR measurements are carried out at $4.2-77 \mathrm{~K}$ with a microwave frequency of $9.4 \mathrm{GHz}$. For photo-EPR, a high-pressure $\mathrm{Hg}$ lamp is used together with appropriate filters to select illumination wavelengths. Light intensity is kept constant within the whole wavelength range. To ensure the same initial conditions, the samples are cooled down in the dark from RT prior to 5-min light illumination. In recharging experiments, the EPR signal intensity is monitored as a function of time at a fixed magnetic field.

Figure 1 illustrates effects of electron irradiation on the EPR spectra. Several sets of EPR signals can be distinguished and are analyzed by the following spin Hamiltonian:

$$
\mathcal{H}=\mu_{B} \mathbf{B g S}+\mathbf{S A I}+\mathbf{S D S} .
$$

Here $\mathbf{S}$ is an effective electron spin, I the nuclear spin, and $\mathbf{B}$ an external magnetic field. $\mu_{B}$ is the Bohr magneton, and $\mathbf{g}$ and $\mathbf{A}$ are the electron $g$ tensor and hyperfine (hf) 


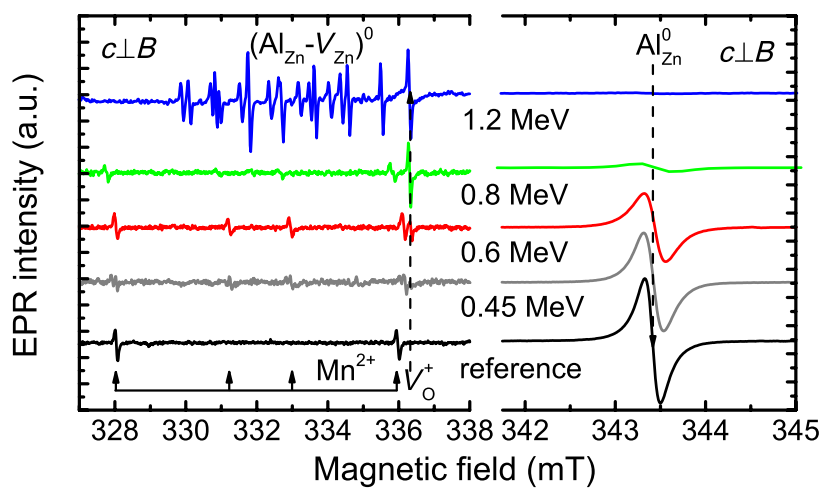

FIG. 1. Effects of electron irradiation on EPR spectra of the investigated samples. The spectra are measured at $30 \mathrm{~K}$ under white-light illumination with an applied magnetic field oriented perpendicular to the $c$ axis of the $\mathrm{ZnO}$ crystal. In the case of the untreated sample, the same EPR spectrum could also be detected in the dark.

tensor, respectively. The tensor $\mathbf{D}$ describes the finestructure splitting for $S>1 / 2$. The obtained spinHamiltonian parameters are summarized in Table I. The spectrum of the reference sample contains two EPR signals that can be attributed to $\mathrm{Mn}^{2+}$ [18] and a shallow donor, $\mathrm{Al}_{\mathrm{Zn}}{ }^{0}$ [19]. The $\mathrm{Mn}^{2+}$ signal is present in all the studied samples before and after irradiation with the same concentration. The $\mathrm{Al}_{\mathrm{Zn}}{ }^{0}$ signal intensity, on the other hand, decreases with increasing irradiation energy. When $E_{\text {irr }} \geq 0.6 \mathrm{MeV}, V_{\mathrm{O}}$ 's are generated, leading to the appearance of a single-line EPR signal from a positively charged $V_{\mathrm{O}}{ }^{+}$[20]. $V_{\mathrm{Zn}}$ 's, on the other hand, start to be formed when $E_{\text {irr }}>0.8 \mathrm{eV}[14,15]$ and can be detected only after the 1.2-MeV irradiation. We note that the EPR signals from the isolated $V_{\mathrm{Zn}}{ }^{-}$are rather weak and can be resolved under monochromatic illumination with photon energies ranging between 2.1 and $2.4 \mathrm{eV}$ (not shown in Fig. 1).

Under white-light illumination, the EPR spectrum is dominated by a new signal consisting of three sets of six equidistant lines, denoted as $\left(\mathrm{Al}_{\mathrm{Zn}}-V_{\mathrm{Zn}}\right)^{0}$ in Fig. 1, which indicates that they stem from a dominant defect formed after the $1.2-\mathrm{MeV}$ irradiation. The observation of six EPR lines for each set implies resolved hf interaction between an electron spin $S=1 / 2$ and a nuclear spin $I=5 / 2$ of $100 \%$ natural abundance. Only three relevant chemical elements fulfill this requirement, namely, $\mathrm{Al}, \mathrm{Mn}$, and I. According to our SIMS data, however, both $\mathrm{Mn}$ and I are below approximately $1 \times 10^{15} \mathrm{~cm}^{-3}$ and only $\mathrm{Al}$ is present with a sufficient concentration to account for the deduced concentrations of the EPR-active centers (see below). Thus, we are dealing with a defect that contains an $\mathrm{Al}$ atom.

Further insight into the defect structure is obtained from angular-dependent EPR studies performed by rotating $\mathbf{B}$ in the $(1 \overline{1} 00)$ and the (1120) planes of the $\mathrm{ZnO}$ crystal. The results, shown by the open circles in Figs. 2(b) and 2(c), are found to exhibit a pattern characteristic for a nonaxial defect with an angle $\varphi=22^{\circ}$ between the defect axis $z$ and the $c$ axis. The simulated angular dependences using the full set of spin-Hamiltonian parameters given in Table I are shown by the solid lines in Figs. 2(b) and 2(c) and are in excellent agreement with the experimental data. The obtained $g$ values $(>2)$ are typical for acceptor-type defects and are very close to those reported for the isolated nonaxial $V_{\mathrm{Zn}}{ }^{-}$. This result strongly suggests that the defect is a complex involving both $V_{\mathrm{Zn}}{ }^{-}$and an $\mathrm{Al}$ atom where the spin density is mainly localized at $V_{\mathrm{Zn}}{ }^{-}$. By taking into account the fact that the hole trapped at $V_{\mathrm{Zn}}{ }^{-}$[21] is centered close to one of the four $\mathrm{O}^{-}$ions surrounding $V_{\mathrm{Zn}}$, the observed tilting angle of $22^{\circ}$ of the defect axis implies that the involved $\mathrm{Al}$ atom resides at the next-nearest $\mathrm{Zn}$ site (i.e., $\mathrm{Al}_{\mathrm{Zn}}$ ) as shown in Fig. 2(d). As the overall character of this defect is acceptorlike, the $\mathrm{Al}_{\mathrm{Zn}}$ (a donor in its isolated form) must have lost an electron to its partner and is in the form of $\mathrm{Al}_{\mathrm{Zn}}{ }^{+}$. This result also justifies hole localization near the farthest $\mathrm{O}$ atom from $\mathrm{Al}_{\mathrm{Zn}}{ }^{+}$[Fig. 2(d)], in view of their electrostatic repulsion. It can therefore be concluded that the EPR-active paramagnetic charge state of the defect is $\left(\mathrm{Al}_{\mathrm{Zn}}{ }^{+}-V_{\mathrm{Zn}}{ }^{-}\right)^{0}$. This defect structure is similar to the socalled $A$ centers in other II-VI materials reported in the literature [22-24].

The paramagnetic $\left(\mathrm{Al}_{\mathrm{Zn}}{ }^{+}-V_{\mathrm{Zn}}{ }^{-}\right)^{0}$ center contains a hole trapped in the $2 p$ orbital of an $\mathrm{O}^{-}$ion, which is subjected to a Stark effect arising from the $V_{\mathrm{Zn}}$ and the $\mathrm{Al}$ atom.

TABLE I. Summary of the spin-Hamiltonian parameters of the defects discussed in this work. The axial components of the electron $\mathbf{g}$ tensor are denoted as $g_{\perp}$ and $g_{\|}$, while the components for the nonaxial centers are given by $g_{x}, g_{y}$, and $g_{z}$. For the nonaxial centers, $\varphi$ is the angle between the $z$ and $c$ axes. The perpendicular and parallel components $A_{\perp}$ and $A_{\|}$of the hyperfine interaction tensor $\mathbf{A}$ and the fine-structure parameter $D$ are given in megahertz. The principal values of the $\mathbf{D}$ tensor are related to $D$ through the relations $D_{z}=2 D / 3$ and $D_{x}=D_{y}=-D / 3$. The parallel and perpendicular directions are with respect to the $c$ axis.

\begin{tabular}{|c|c|c|c|c|c|c|c|c|}
\hline Center & $S$ & $I$ & $g_{x}\left(g_{\perp}\right) g_{y}$ & $g_{z}\left(g_{\|}\right)$ & $\left|A_{\perp}\right|$ & $\left|A_{\|}\right|$ & $D$ & $\varphi(\mathrm{deg})$ \\
\hline$V_{\mathrm{Zn}}{ }^{-}$(axial) & $1 / 2$ & & 2.0193 & 2.0041 & & & & \\
\hline$V_{\mathrm{Zn}}{ }^{-}$(nonaxial) & $1 / 2$ & & 2.01732 .0183 & 2.0041 & & & & 110.75 \\
\hline$\left(\mathrm{Al}_{\mathrm{Zn}}-V_{\mathrm{Zn}}\right)^{0}$ & $1 / 2$ & $5 / 2$ & 2.02432 .0143 & 2.0045 & 26.1 & 26.1 & & 22 \\
\hline$V_{\mathrm{O}}^{+}$ & $1 / 2$ & & 1.9960 & 1.9945 & & & & \\
\hline $\mathrm{Al}_{\mathrm{Zn}}{ }^{0}$ & $1 / 2$ & $5 / 2$ & 1.9563 & 1.9577 & 2.010 & 2.010 & & \\
\hline $\mathrm{Mn}^{2+}$ & $5 / 2$ & $5 / 2$ & 2.0016 & 2.0016 & 227.8 & 227.8 & -650.2 & \\
\hline
\end{tabular}



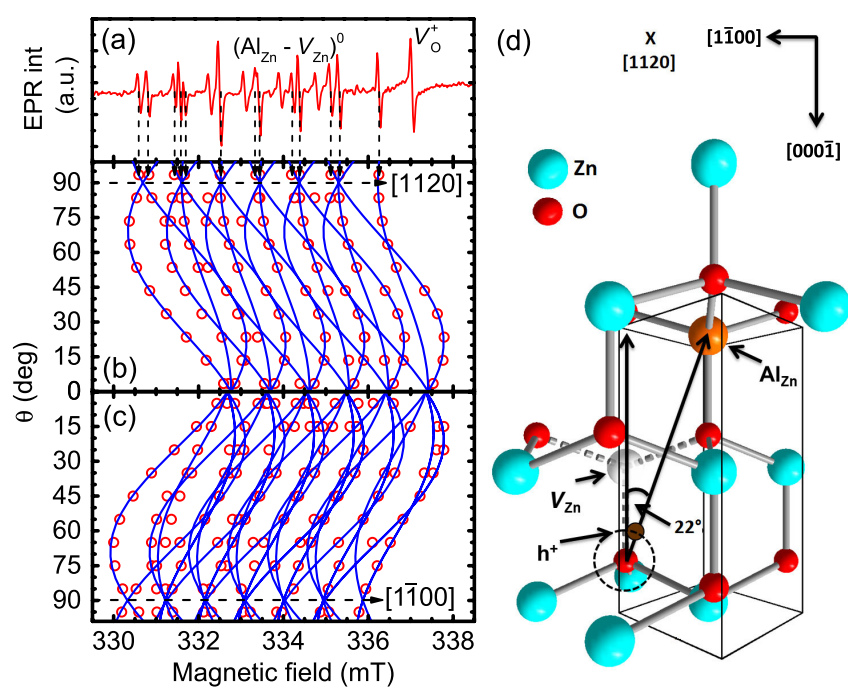

FIG. 2. (a) EPR spectrum of the 1.2-MeV irradiated sample measured at $77 \mathrm{~K}$ under white-light illumination with an applied magnetic field $\mathbf{B}$ oriented parallel to the [1120] axis. The anisotropy of the EPR signal is shown for rotation of $\mathbf{B}$ from the [0001] axis to the [1120] axis in the (1100) plane (b) and from the [0001] axis to the [1 100$]$ axis in the (1120) plane (c). The open circles (red online) represent the experimental positions of the EPR lines, and the solid lines (blue online) are simulation results using the spin Hamiltonian in Eq. (1) with the parameters given in Table I. (d) Atomic arrangement of the $V_{\mathrm{Zn}}-\mathrm{Al}_{\mathrm{Zn}}$ complex.

Neglecting the spin-orbit interaction, the axial field from $V_{\mathrm{Zn}}$ is expected to split the threefold orbital degeneracy of the $2 p$ state into a lower-energy singlet $p_{z}$ and a higherenergy doublet with $p_{x}, p_{y}$. An additional crystal field induced by the $\mathrm{Al}_{Z \mathrm{n}}$ partner pointing away from the $c$ axis should further lift the orbital degeneracy of the doublet state. By including the spin-orbit interaction in the first and second order, the deviations of the $g$-tensor components $g_{x}, g_{y}$, and $g_{z}$ from the free-electron $g$ value $g_{0}$ can be described as [22]

$$
\begin{aligned}
\delta g_{x(y)} & =-\frac{2 \lambda}{\Delta_{y(x)}}-\lambda^{2}\left[\frac{g_{0}}{2} \frac{1}{\Delta_{x(y)}^{2}}+\frac{1}{\Delta_{x} \Delta_{y}}\right], \\
\delta g_{z} & =-\lambda^{2}\left[\frac{g_{0}}{2}\left(\frac{1}{\Delta_{x}^{2}}+\frac{1}{\Delta_{y}^{2}}\right)-\frac{1}{\Delta_{x} \Delta_{y}}\right] .
\end{aligned}
$$

Here $\Delta_{x}\left(\Delta_{y}\right)$ are energies of $p_{x}\left(p_{y}\right)$ relative to $p_{z}$, and $\lambda$ is the spin-orbit coupling constant of the $\mathrm{O}^{-}$ion. By using $\lambda=-16 \mathrm{meV}$ [25], Eq. (2) yields a positive shift from the free-electron $g$ factor that is expected for an acceptor-type defect with $g_{x}>g_{y}>g_{z} \approx g_{0}$, consistent with the experimentally determined $g$ values for the $\mathrm{Al}_{\mathrm{Zn}}-V_{\mathrm{Zn}}$ complex. $\Delta_{x}\left(\Delta_{y}\right)$ can be estimated as being $2.6(1.44 \mathrm{eV})$, which is comparable to the values deduced by Schirmer for the substitutional Li acceptor [25].

The distribution of the spin density within the $\mathrm{Al}_{\mathrm{Zn}}-V_{\mathrm{Zn}}$ complex can be further evaluated based on the determined
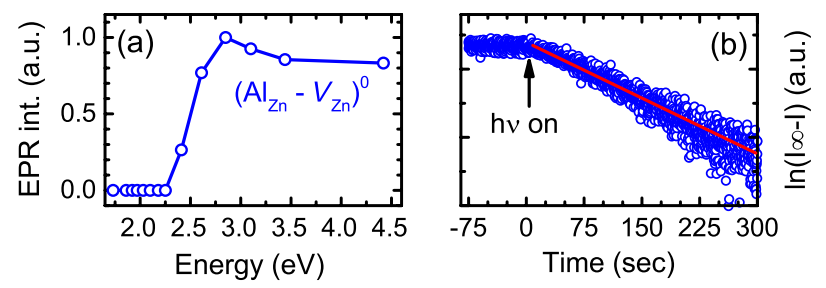

FIG. 3. (a) Intensity of the $\left(\mathrm{Al}_{\mathrm{Zn}}-V_{\mathrm{Zn}}\right)^{0} \mathrm{EPR}$ signal (open circles) as a function of the photon energy of light illumination. The line is a guide to the eye. (b) Time-dependent behavior of the $\left(\mathrm{Al}_{\mathrm{Zn}}-V_{\mathrm{Zn}}\right)^{0}$ signal after switching on the light. The $y$ axis displays the difference of the measured EPR intensity $(I)$ from the saturation value $\left(I_{\infty}\right)$ presented in a logarithmic scale. The linear slope shown by the solid line (red online) indicates a monoexponential process due to direct recharging.

hf coupling parameter $A$. By employing a one-electron linear combination of the atomic orbital scheme [26] and the charge density of the $3 s$ electron $\left|\psi_{3 s}(0)\right|^{2}=3911 \mathrm{MHz}$ for a free neutral $\mathrm{Al}$ atom [27], the localization of the electron wave function at the $\mathrm{Al}$ ion is estimated to be $0.7 \%$, i.e., rather weak. This result is consistent with the strong localization of spin density at the $V_{\mathrm{Zn}}{ }^{-}$part of the complex. In principle, the $p$-type character of the hole wave function should lead to an anisotropic hf tensor, which is not observed in this case. However, previous studies of the $A$ centers in other II-VI materials [22] and of vacancy-donor pairs in Si [28] show that this anisotropy is rather weak and is not always resolved experimentally.

The energy level position of the $\mathrm{Al}_{\mathrm{Zn}}-V_{\mathrm{Zn}}$ complex can be determined from photo-EPR measurements. The corresponding EPR signal can be detected only when the photon energy exceeds $2.4 \mathrm{eV}$, as shown in Fig. 3(a). Moreover, the recharging process exhibits a monoexponential behavior [Fig. 3(b)] which proves that it is a result of a single photoionization process. Since the EPR signal from the isolated $\mathrm{Al}_{\mathrm{Zn}}{ }^{0}$ also increases under the light illumination with the same photon energy, the responsible photoionization process should be connected with the conduction band, i.e.,

$$
\left(\mathrm{Al}_{\mathrm{Zn}}-V_{\mathrm{Zn}}\right)^{-}+h \nu \rightarrow\left(\mathrm{Al}_{\mathrm{Zn}}-V_{\mathrm{Zn}}\right)^{0}+e .
$$

This process places the $(0 /-)$ level of the $\mathrm{Al}_{\mathrm{Zn}}-V_{\mathrm{Zn}}$ complex at approximately $1 \mathrm{eV}$ above the top of the valence band $\left(E_{v}\right)$ and confirms that the defect is a deep acceptor. Indeed, these results are consistent with the data obtained from density-functional theory (DFT) calculations by Thienprasert et al. [11] and our calculations [29], which predict $\mathrm{Al}_{\mathrm{Zn}}-V_{\mathrm{Zn}}$ to be a deep single acceptor with a lower formation energy relative to the sum of that of the two individual constituents (see Refs. [29,30] for more details on our DFT calculations).

To further shed light on the formation of the $\mathrm{Al}_{\mathrm{Zn}}-V_{\mathrm{Zn}}$ center, we carry out a quantitative EPR study. The total 


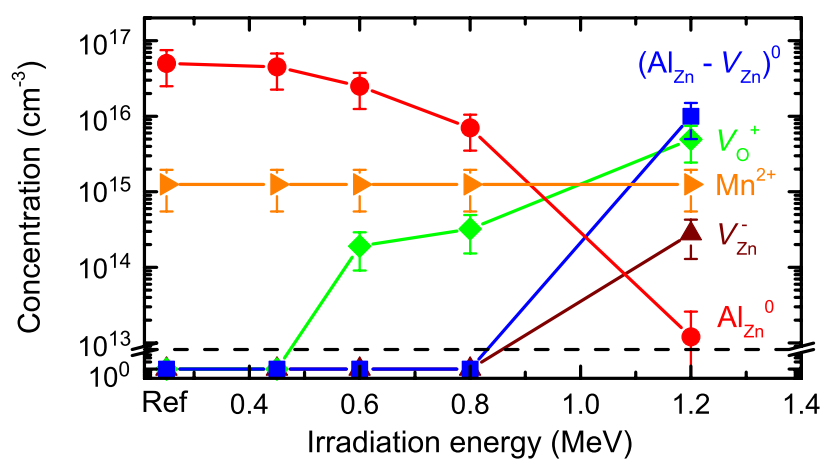

FIG. 4. Concentrations of the $V_{\mathrm{Zn}}{ }^{-},\left(\mathrm{Al}_{\mathrm{Zn}}-V_{\mathrm{Zn}}\right)^{0}, V_{\mathrm{O}}{ }^{+}, \mathrm{Al}_{\mathrm{Zn}}{ }^{0}$, and $\mathrm{Mn}^{2+}$ centers determined from the quantitative EPR measurements as a function of the electron irradiation energy.

number of $V_{\mathrm{Zn}}$-related defects in the 1.2-MeV irradiated sample is about $1 \times 10^{16} \mathrm{~cm}^{-3}$ whereas it is below $10^{13} \mathrm{~cm}^{-3}$ in the untreated material-see Fig. 4. These values are in good agreement with the results of positron annihilation spectroscopy (PAS) [15] which show that the concentration of the open-volume defects related to $V_{\mathrm{Zn}}$ is below the PAS detection limit of $1 \times 10^{15} \mathrm{~cm}^{-3}$ prior to the irradiation but increases up to approximately $6 \times 10^{15} \mathrm{~cm}^{-3}$ after the $1.2-\mathrm{MeV}$ irradiation. The formation of the $\mathrm{Al}_{\mathrm{Zn}}-V_{\mathrm{Zn}}$ center implies migration of $\mathrm{Al}_{\mathrm{Zn}}$ and/or $V_{\mathrm{Zn}} \cdot \mathrm{Al}_{\mathrm{Zn}}$ is, however, known to be practically immobile at temperatures below approximately $800^{\circ} \mathrm{C}$ [31], and $V_{\mathrm{Zn}}$ is stable at RT $[4,32]$ with the calculated migration energy barrier of $1.4 \mathrm{eV}$ for $V_{\mathrm{Zn}}{ }^{2-}$ [33]. Though the electron irradiation of our samples is performed at RT, the energy required for migration of the constituting species may be provided by the irradiation itself, promoting the formation of the $\mathrm{Al}_{\mathrm{Zn}}-V_{\mathrm{Zn}}$ center. Such irradiation-enhanced migration is well documented in other semiconductors, e.g., Si [34].

Most importantly, our quantitative EPR measurements prove that the $\mathrm{Al}_{Z \mathrm{n}}-V_{\mathrm{Zn}}$ complex is one of the most energetically favorable defects in $\mathrm{ZnO}$ in the presence of both $V_{\mathrm{Zn}}$ and $\mathrm{Al}_{\mathrm{Zn}}$. The formation of this complex binds more than $90 \%$ of the stable $V_{\mathrm{Zn}}$ 's which survive Frenkel pair recombination-see Fig. 4. This process is accompanied by a sharp decline in the concentration of the isolated $\mathrm{Al}_{\mathrm{Zn}}$, giving further evidence that $\mathrm{Al}_{\mathrm{Zn}}$ is indeed a partner of the complex. We note that the total $\mathrm{Al}$ concentration determined by SIMS is about $3 \times 10^{16} \mathrm{~cm}^{-3}$, which is comparable, within the experimental error, with the concentration of the $\mathrm{Al}_{\mathrm{Zn}}-V_{\mathrm{Zn}}$ center. The formation of the $\mathrm{Al}_{\mathrm{Zn}}-V_{\mathrm{Zn}}$ complex should thus suppress the $n$-type conductivity, since the complex not only acts as a compensating acceptor but also binds one shallow $\mathrm{Al}_{\mathrm{Zn}}$ donor during its formation, thereby literally deactivating the $n$-doping function of $\mathrm{Al}_{\mathrm{Zn}}$. Such a decline in the electron concentration has indeed been observed from Hall-effect measurements [15]. We thus suggest that such donor-vacancy complexes could severely degrade performance of highly doped $n$-type $\mathrm{ZnO}$ films as TCO, since the formation energy of $V_{\mathrm{Zn}}$ is reduced in $n$-type materials, especially when they are grown under O-rich conditions [12,13,33,35]. This conclusion is further supported by both our [29] and other DFT calculations of the formation energy of the $\mathrm{Al}_{\mathrm{Zn}}-V_{\mathrm{Zn}}$ complex [11]. In addition, such performance degradation was observed not only in $\mathrm{ZnO}$ highly doped with $\mathrm{Al}$ [9], but also for other group-III elements [10]. This observation is further evidence that donor-vacancy centers play a crucial role for controlling the $n$-type doping limit in $\mathrm{ZnO}$ in general.

Finally, the general validity of the present results is further corroborated by comparison with data obtained by other authors for the evolution of point defects on the $\mathrm{Zn}$ sublattice using different types of $\mathrm{ZnO}$ materials and different characterization techniques. Especially, in a comprehensive series of PAS studies of MeV electron-irradiated $\mathrm{ZnO}$ samples grown by the seeded vapor phase technique, with $\mathrm{H}$ and $\mathrm{Al}$ as the most likely residual impurities having concentrations in the $10^{17}-\mathrm{cm}^{-3}$ range, Tuomisto et al. $[7,8]$ investigate the introduction and thermal stability of openvolume defects. Similar to our findings, they report (i) a relatively low introduction rate of defects on the $\mathrm{Zn}$ sublattice, indicating strong recombination between $V_{\mathrm{Zn}}$ and $\mathrm{Zn}$ interstitials, (ii) a deep-acceptor behavior of $V_{\mathrm{Zn}}$ with an ionization level located approximately $2.3 \mathrm{eV}$ below $E_{c}$, and (iii) $V_{\mathrm{Zn}}$ 's to be part of two different defects. The latter is inferred from isochronal annealing data, showing that the $V_{\mathrm{Zn}}$ 's disappear in two separate stages at approximately 400 and $550 \mathrm{~K}$ with activation energies of approximately 1.3 and $1.8 \mathrm{eV}$, respectively. Since the PAS signature of the $\mathrm{Al}_{\mathrm{Zn}}-V_{\mathrm{Zn}}$ defect configuration shown in Fig. 2(d) is anticipated to be very similar (or even indistinguishable within the experimental accuracy) to that of the isolated $V_{\mathrm{Zn}}$, the two-stage annealing of $V_{\mathrm{Zn}}$ can be explained readily as follows: the first stage is due to migration of $V_{\mathrm{Zn}}$ and subsequent trapping or annihilation by other defects or impurities, while the second stage arises from dissociation of the $\mathrm{Al}_{\mathrm{Zn}}-V_{\mathrm{Zn}}$ complex followed by migration and trapping or annihilation of the released $V_{\mathrm{Zn}}$ 's. As discussed previously, an activation energy of approximately $1.3 \mathrm{eV}$ is in the range of that expected for the migration of $V_{\mathrm{Zn}}[4,32,33]$, and with a binding energy of approximately $0.5 \mathrm{eV}$ for the $\mathrm{Al}_{\mathrm{Zn}}-V_{\mathrm{Zn}}$ complex, as predicted by DFT calculations (see Refs. [11,29]), the second stage will exhibit a total energy barrier of approximately $1.8 \mathrm{eV}$, in perfect agreement with the experimental value in Ref. [8].

In summary, we employ EPR spectroscopy to investigate properties of $\mathrm{Al}_{\mathrm{Zn}}$ and intrinsic defects that were introduced in monocrystalline $\mathrm{ZnO}$ in a controlled manner by electron irradiation. For irradiation energies exceeding the displacement threshold for the $\mathrm{Zn}$ sublattice, one of the dominant irradiation-induced defects is unambiguously identified as the $\mathrm{Al}_{\mathrm{Zn}}-V_{\mathrm{Zn}}$ complex. The complex is concluded to be energetically preferable over the isolated $V_{\mathrm{Zn}}$, and most of the available $\mathrm{Al}_{\mathrm{Zn}}$ and $V_{\mathrm{Zn}}$ are bound during its formation. 
The center is further shown to act as a deep acceptor and has the $(0 /-)$ energy level located at about $1.0 \mathrm{eV}$ above $E_{v}$. We further show that our results are of general relevance, irrespective of the type of $\mathrm{ZnO}$ material used. Our findings underline the important role of such donorvacancy complexes in limiting $n$-type doping efficiency and thus the performance of $\mathrm{ZnO}$ as TCO. In fact, similar effects caused by interaction with $V_{\mathrm{Zn}}$ are also anticipated for other shallow $n$-type dopants in $\mathrm{ZnO}$, and the present results could serve as a general guideline for future steps to improve $n$-type doping efficiency and conductivity during materials growth.

\section{ACKNOWLEDGMENTS}

Discussions with Dr. K. E. Knutsen and Professor A. Yu. Kuznetsov during the initial stage of this work are highly appreciated. Financial support by the Swedish Research Council (Grant No. 621-2010-3971) and Norwegian Research Council through the FRINATEK program (WEDD and DYNAZOx projects) is gratefully acknowledged.

[1] A. Janotti and C. G. Van de Walle, Fundamentals of zinc oxide as a semiconductor, Rep. Prog. Phys. 72, 126501 (2009).

[2] U. Ozgur, Y. I. Alivov, C. Liu, A. Teke, M. A. Reshchikov, S. Dogan, V. Avrutin, S.-J. Cho, and H. Morkoc, A comprehensive review of $\mathrm{ZnO}$ materials and devices, J. Appl. Phys. 98, 041301 (2005).

[3] S. J. Pearton and F. Ren, Advances in ZnO-based materials for light emitting diodes, Curr. Opin. Chem. Eng. 3, 51 (2014).

[4] X. J. Wang, L. S. Vlasenko, S. J. Pearton, W. M. Chen, and I. A. Buyanova, Oxygen and zinc vacancies in as-grown ZnO single crystals, J. Phys. D 42, 175411 (2009).

[5] J. E. Stehr, S. L. Chen, N. Koteeswara Reddy, C. W. Tu, W. M. Chen, and I. A. Buyanova, Turning $\mathrm{ZnO}$ into an efficient energy upconversion material by defect engineering, Adv. Funct. Mater. 24, 3760 (2014).

[6] E. H. Khan, M. H. Weber, and M. D. McCluskey, Formation of isolated $\mathrm{Zn}$ vacancies in $\mathrm{ZnO}$ single crystals by absorption of ultraviolet radiation: A combined study using positron annihilation, photoluminescence, and mass spectroscopy, Phys. Rev. Lett. 111, 017401 (2013).

[7] F. Tuomisto, V. Ranki, K. Saarinen, and D. C. Look, Evidence of the $\mathrm{Zn}$ vacancy acting as the dominant acceptor in n-type ZnO, Phys. Rev. Lett. 91, 205502 (2003).

[8] F. Tuomisto, K. Saarinen, D. C. Look, and G. C. Farlow, Introduction and recovery of point defects in electronirradiated ZnO, Phys. Rev. B 72, 085206 (2005).

[9] J. G. Lu, Z. Z. Ye, Y. J. Zeng, L. P. Zhu, L. Wang, J. Yuan, B. H. Zhao, and Q. L. Liang, Structural, optical, and electrical properties of $(\mathrm{Zn}, \mathrm{Al}) \mathrm{O}$ films over a wide range of compositions, J. Appl. Phys. 100, 073714 (2006).
[10] T. Minami, H. Sato, H. Nanto, and S. Takata, Group III impurity doped zinc oxide thin films prepared by rf magnetron sputtering, Jpn. J. Appl. Phys. 24, L781 (1985).

[11] J. T. Thienprasert, S. Rujirawat, W. Klysubun, J. N. Duenow, T. J. Coutts, S. B. Zhang, D. C. Look, and S. Limpijumnong, Compensation in Al-doped $\mathrm{ZnO}$ by Al-related acceptor complexes: Synchrotron x-ray absorption spectroscopy and theory, Phys. Rev. Lett. 110, 055502 (2013).

[12] D. C. Look, K. D. Leedy, L. Vines, B. G. Svensson, A. Zubiaga, F. Tuomisto, D. R. Doutt, and L. J. Brillson, Self-compensation in semiconductors: The $\mathrm{Zn}$ vacancy in Ga-doped ZnO, Phys. Rev. B 84, 115202 (2011).

[13] J.-Y. Noh, H. Kim, Y.-S. Kim, and C. H. Park, Electron doping limit in Al-doped $\mathrm{ZnO}$ by donor-acceptor interactions, J. Appl. Phys. 113, 153703 (2013).

[14] D. R. Locker and J. M. Meese, Displacement thresholds in ZnO, IEEE Trans. Nucl. Sci. 19, 237 (1972).

[15] K. E. Knutsen, A. Galeckas, A. Zubiaga, F. Tuomisto, G. C. Farlow, B. G. Svensson, and A. Y. Kuznetsov, Zinc vacancy and oxygen interstitial in $\mathrm{ZnO}$ revealed by sequential annealing and electron irradiation, Phys. Rev. B 86, 121203 (2012).

[16] J. E. Stehr, B. K. Meyer, and D. M. Hofmann, Magnetic resonance of impurities, intrinsic defects and dopants in ZnO, Appl. Magn. Reson. 39, 137 (2010).

[17] M. D. McCluskey and S. J. Jokela, Sources of n-type conductivity in ZnO, Physica (Amsterdam) 401B-402B, 355 (2007).

[18] P. Dorain, Electron paramagnetic resonance of manganese (II) in hexagonal zinc oxide and cadmium sulfide single crystals, Phys. Rev. 112, 1058 (1958).

[19] F. Herklotz, E. V. Lavrov, J. Weber, G. V. Mamin, Y. S. Kutin, M. A. Volodin, and S. B. Orlinskii, Identification of shallow Al donors in ZnO, Phys. Status Solidi (b) 248, 1532 (2011).

[20] J. M. Smith and W. E. Vehse, ESR of electron irradiated $\mathrm{ZnO}$ confirmation of the $\mathrm{F}+$ center, Phys. Lett. A 31, 147 (1970).

[21] D. Galland and A. Herve, ESR spectra of the zinc vacancy in ZnO, Phys. Lett. A 33, 1 (1970).

[22] J. Schneider, B. Dischler, and A. Räuber, Defects in ZnS/ ZnSe mixed crystals-II. The paramagnetic A-centers in cubic $\mathrm{ZnS}_{1-x} \mathrm{Se}_{x}$, J. Phys. Chem. Solids 31, 337 (1970).

[23] J. Bittebierre and R. Cox, Possible identification of zincvacancy-donor-impurity complexes in zinc telluride by optically detected magnetic resonance, Phys. Rev. B 34, 2360 (1986).

[24] A. Räuber and J. Schneider, Electron spin resonance of a luminescent center in aluminium-activated cubic $\mathrm{ZnS}$ single crystals, Phys. Lett. 3, 230 (1963).

[25] O.F. Schirmer, The structure of the paramagnetic lithium center in zinc oxide and beryllium oxide, J. Phys. Chem. Solids 29, 1407 (1968).

[26] J. Morton and K. Preston, Atomic parameters for paramagnetic resonance data, J. Magn. Reson. 30, 577 (1978).

[27] J. Fitzpatrick, F. R. Manby, and C. M. Western, The interpretation of molecular magnetic hyperfine interactions, J. Chem. Phys. 122, 084312 (2005).

[28] E. L. Elkin and G. D. Watkins, Defects in irradiated silicon: Electron paramagnetic resonance and electron-nuclear 
double resonance of the arsenic- and antimony-vacancy pairs, Phys. Rev. 174, 881 (1968).

[29] See Supplemental Material at http://link.aps.org/ supplemental/10.1103/PhysRevApplied.2.021001 for a more detailed description of our DFT calculations.

[30] T. S. Bjørheim, S. Erdal, K. M. Johansen, K. E. Knutsen, and $\mathrm{T}$. Norby, $\mathrm{H}$ and $\mathrm{Li}$ related defects in $\mathrm{ZnO}$ and their effect on electrical properties, J. Phys. Chem. C 116, 23764 (2012).

[31] V. J. Norman, The diffusion of aluminium and gallium in zinc oxide, Australian Journal of Chemistry 22, 325 (1969).
[32] N. T. Son, G. Ivanov, A. Kuznetsov, B. G. Svensson, Q. X. Zhan, M. Willander, N. Morishita, T. Ohshima, H. Itoh, J. Isoya, E. Janzén, and R. Yakimova, Recombination centers in as-grown and electron-irradiated $\mathrm{ZnO}$ substrates, J. Appl. Phys. 102, 093504 (2007).

[33] A. Janotti and C. G. Van de Walle, Native point defects in ZnO, Phys. Rev. B 76, 165202 (2007).

[34] Deep Centers in Semiconductors, edited by S. T. Pantelides (Gordon and Breach, New York, 1986), pp. 177-214.

[35] S. Lany and A. Zunger, Dopability, intrinsic conductivity, and nonstoichiometry of transparent conducting oxides, Phys. Rev. Lett. 98, 045501 (2007). 